\title{
Estudo Sobre Indicadores de Produção Científica Versus Produção Tecnológica na Universidade Estadual de Maringá
}

\author{
Study on Scientific Production Indicators Versus Technological \\ Production at Universidade Estadual de Maringá
}

\begin{abstract}
Resumo
Atualmente existem muitas discussões acerca da pesquisa científica e inovação e sobre como esses termos se interrelacionam dentro da universidade. Neste sentido, considerando-se que seja importante promover reflexões sobre mecanismos de apropriação do conhecimento produzido nas universidades para sua conversão em inovação para a sociedade. O objetivo deste trabalho foi avaliar a produção científica e tecnológica na Universidade Estadual de Maringá. A metodologia utilizada consistiu numa pesquisa documental em bases de dados científicas e bancos de patentes do portal de periódicos eletrônicos da Capes, considerando-se para as buscas o período de 2008-2018. Os resultados apontaram que existe um hiato entre produção tecnológica e produção científica, observando-se que o número de depósitos de pedidos de patentes está muito aquém do número de documentos científicos produzidos. Conclui-se que, apesar do arcabouço legal e dos incentivos à inovação, a universidade ainda apresenta uma cultura acadêmica de baixa proteção de suas invenções.
\end{abstract}

Palavras-chave: Produção científica. Produção tecnológica. Inovação.

\begin{abstract}
There are currently many discussions about scientific research and innovation and how these terms interrelate within the university. Considering that it is important to promote reflections on mechanisms of appropriation of knowledge produced in universities for its conversion into innovation for society, the objective of this work was to evaluate the scientific and technological production at the Universidade Estadual de Maringá. The methodology used consisted of a documentary research in scientific databases and patent banks of the Capes electronic journals portal, considering the search period 2008-2018. The results indicated that there is a gap between technological production and scientific production, noting that the number of patent filings is far below the number of scientific documents produced. It is concluded that despite the legal framework and the incentives for innovation, the university still has an academic culture of low protection from its inventions.
\end{abstract}

Keywords: Scientific production. Technological production. Innovation

Área Tecnológica: Indicadores de Inovação. Patentes. Inovação e Desenvolvimento. 


\section{Introdução}

O Empreendedorismo, a Inovação e a Propriedade Intelectual são temas cada vez mais discutidos no meio acadêmico e sua importância para o pesquisador já é reconhecida pelo Conselho Nacional de Desenvolvimento Científico e Tecnológico (CNPq), uma agência do Ministério da Ciência, Tecnologia e Inovação (MCTI). Para Nunes et al. (2013), este reconhecimento pode ser observado ao se visualizar a inclusão no menu dos tópicos "Patentes e Registros" e "Inovação" disponíveis atualmente na Plataforma Lattes e, também, a criação do formulário eletrônico FORMICT (Formulário para Informações sobre a Política de Propriedade Intelectual das Instituições Científicas e Tecnológicas do Brasil) pelo MCTI, que, desde 2012, possibilita que as instituições científicas e tecnológicas (ICTs) encaminhem informações sobre suas políticas de propriedade intelectual, proteções requeridas e concedidas e contratos de licenciamento ou de transferência de tecnologia firmados, atendendo ao disposto no Art. 17 da Lei de Inovação - Lei n. 10.973/2004 (BRASIL, 2004).

É muito importante debater sobre a apropriação do conhecimento produzido nas universidades e sobre as formas de convertê-lo em produtos comercializáveis e inovações que beneficiem a sociedade. Nesse sentido, de acordo com Cativelli e Lucas (2016), a patente é a publicação capaz de proteger tanto a descrição do conhecimento científico descoberto quanto a sua aplicação, embora, segundo os autores, este ainda seja um recurso pouco requerido pelas instituições de ensino e seus pesquisadores, que preferem publicar artigos científicos em revistas indexadas. Entende-se como produção científica o resultado da pesquisa básica, também chamada de pesquisa pura ou fundamental, que apresenta como resultados, em sua maioria, artigos científicos publicados em revistas especializadas e indexadas. Já a produção tecnológica, é o produto da pesquisa aplicada e experimental, que, diferentemente da pesquisa básica, visa não apenas à geração do conhecimento, mas a sua aplicação prática, resultando em novas tecnologias.

Assim, ao se verificar o volume de publicações científicas revisadas por pares e o volume de depósitos de pedidos de patentes pode-se obter alguns indicadores sobre a capacidade científica e tecnológica de uma instituição ou de um determinado local do país ou do mundo. Atualmente, as universidades brasileiras vêm sofrendo cada vez mais críticas em relação à falta de fomento para as pesquisas básicas e se encontram numa situação singular, que parece promover a importância de repensar a aceitação da introdução da inovação dentro das universidades $e$ explorar um pouco os benefícios da inovação aplicada à sociedade.

Diante deste panorama teve-se como motivação buscar alguns apontamentos quantitativos para entender como as universidades brasileiras têm evoluído no quesito produção tecnológica em relação ao percentual de crescimento no número de patentes depositadas pelas universidades brasileiras após a criação de mecanismos e de um arcabouço legal de incentivo à inovação. Nesse sentido, o objetivo deste trabalho é avaliar a evolução da produção científica e da produção tecnológica na Universidade Estadual de Maringá - UEM, na última década, 2008-2018. Entretanto, para uma melhor análise dos indicadores, se fez necessário, também, buscar um melhor entendimento sobre o termo Inovação tecnológica. Assim, dentre os procedimentos metodológicos adotados, além de buscas em bases de dados de periódicos científicos e bancos de patentes, realizou-se uma revisão da literatura. 


\section{Revisão da Literatura}

\subsection{Desmistificando a Inovação}

Comumente, o termo inovação vem sendo utilizado equivocadamente e, muitas vezes, é confundido com os conceitos de invenção, patentes, ideias novas e criatividade. Contudo, como ressaltam De Bes e Kotler (2011), ideias e criatividade sozinhas não são suficientes para se converter em inovação. A seguir, realiza-se uma breve explanação para distinção dos termos que serão discutidos mais adiante:

a) Inovação versus Invenção - são termos complementares, porém diferentes. A invenção é apenas o primeiro passo do processo de converter uma ideia em algo útil e inovador, enquanto a inovação é o processo de transformar ideias e fazê-las evoluir técnica e comercialmente, ou seja, a ponto de terem amplo uso prático (TIDD; BESSANT; PAVIT, 2009). Assim, um registro de patente concedido, mas cujo produto ainda não é desenvolvido comercialmente, não é inovação.

b) Inovação versus Tecnologia - para Carvalho, Reis e Cavalcante (2011), a tecnologia é a aplicação do conhecimento convertida em um bem, transferível e comercializável. Por sua vez, "a inovação está associada à introdução, com êxito, de um produto (ou serviço) no mercado ou de um processo, método ou sistema na organização" (CARVALHO; REIS; CAVALCANTE, 2011, p. 25).

A criatividade e a geração de novas ideias, por sua vez, são consideradas como alimento para o complexo processo de inovação, e assim, são incapazes de se converterem em inovação isoladamente.

\subsection{Produção Científica e Tecnológica nas Universidades Brasileiras}

O volume de publicações revisadas por pares e o número de pedidos de patentes depositados podem fornecer informações sobre o desenvolvimento da capacidade científica e tecnológica em todo o mundo. Analisando o desempenho brasileiro no quesito produção científica, um estudo realizado pelo Ministério da Ciência, Tecnologia, Inovações e Comunicações - MCTIC (2017), utilizando periódicos científicos indexados pela Scopus, constatou o crescimento expressivo do Brasil, que aumenta sua participação na produção científica mundial a cada ano.

Na mesma linha de pesquisa, um estudo de Cross, Thomson e Sinclair (2017) para a Coordenação de Aperfeiçoamento de Pessoal de Nível Superior - Capes, considerando artigos indexados na base de dados da Web of Science, revelou o Brasil como o $13^{\circ}$ país do mundo em termos de número de artigos científicos produzidos entre 2011 e 2016. Os estudos convergem e ratificam o crescimento do número de publicações científicas brasileiras e o aumento de sua participação frente ao total mundial de publicações.

Quanto à produção tecnológica, as universidades figuram com papel de destaque frente aos depósitos de pedidos de patentes no país. Segundo Jorge et al. (2018), numa análise de 
estatísticas do INPI, entre os dez maiores depositantes de patentes de invenções residentes no país, as universidades dominaram as primeiras posições.

No entanto, mesmo representando um percentual considerável no total de pedidos de patentes no país, as universidades brasileiras ainda não exploram todo o seu potencial tecnológico, e a publicação científica ainda é a prioridade dos pesquisadores acadêmicos. Diferentemente de muitos países, como a China, por exemplo, que é a líder em produção científica mundial e possui um proporcional número de depósitos de pedidos de patentes após um expressivo crescimento nas últimas décadas (GAO et al., 2010).

Nunes e Oliveira (2007), em um estudo para o INPI, concluem que a Propriedade Industrial (PI) ainda é pouco conhecida e percebida pelo meio acadêmico no Brasil, fato ainda mais preocupante quando se contabilizam os recursos investidos em pesquisas pelas universidades no país, sem que haja preocupação com a proteção destes desenvolvimentos através de patentes, bem como sua transferência para o mercado e seu uso pela sociedade. Para os autores, tudo isso traz como consequências a falta de proteção de tecnologias que poderiam ter aplicação comercial pelas empresas e a não utilização das informações disponíveis no documento de patentes, que constituem uma fonte de informação importante para auxiliar outras pesquisas.

Nunes e Oliveira (2007) salientam ainda, que, dentre as consequências resultantes do desconhecimento do sistema de Propriedade Intelectual pelas instituições de ensino superior no Brasil, estão a não apropriação de tecnologias patrocinadas com recursos públicos, a falta de remuneração e reconhecimento aos pesquisadores pelos desenvolvimentos realizados, a ausência de divulgação para a sociedade do acervo tecnológico produzido na academia, bem como o crescente dispêndio das empresas com a aquisição de tecnologias exógenas.

O estudo de Martins (2010) acerca do tema identificou que dentre os principais fatores que levaram a um baixo índice de patenteamento das tecnologias desenvolvidas nas instituições de ensino se destaca o desconhecimento sobre o sistema de patentes e a Lei de Inovação por parte da maioria dos pesquisadores.

Gimenez e Bonacelli (2013) advertem que a Universidade tem sido convidada a dialogar com o setor produtivo e participar mais ativamente do desenvolvimento econômico. Para os autores, isso a tem provocado a repensar e a redefinir o seu papel em busca de um novo "modelo", o qual chamam de terceira missão.

Mueller e Perucchi (2014) realçam que a questão da produção de patentes como resultado de pesquisas acadêmicas é um tema polêmico por envolver discussões sobre o papel da universidade e de pesquisadores acadêmicos na produção de conhecimento dirigido à utilização de tecnologias aplicáveis à solução de problemas sociais. Para os autores, deve-se atentar ainda que há muitas discussões relacionados à ética no ganho privado a partir de pesquisa na universidade, financiada com verbas públicas.

Cativelli e Lucas (2016) destacam que, na publicação de um artigo científico, os autores figuram num papel de destaque e a instituição de ensino num papel secundário; com a patente acontece o contrário: o protagonismo fica com a instituição a qual pertencem os inventores. De acordo com a Lei de Propriedade Industrial, Lei n. 9.279/1996 (BRASIL, 1996), em seu artigo 88, pertence ao empregador a patente que decorrer de contrato de trabalho cuja execução ocorra no Brasil $e$ que tenha por objeto a pesquisa ou a atividade inventiva. Assim, o pedido de patente de uma invenção cujos inventores são pesquisadores acadêmicos deve ser requerido pela instituição 
de ensino a qual pertencem, que deterá a sua titularidade, ou seja, a propriedade da invenção. Além de outros fatores, como o desconhecimento acerca da Propriedade Intelectual e a inexistência de políticas de incentivos aos pesquisadores, para Cativelli e Lucas (2016), a questão da titularidade da patente afeta o ego do pesquisador $e$ torna-se um fator influenciador para a preferência pela publicação de artigos em detrimento do patenteamento. Nessa linha de pensamento, Muller e Perucchi (2014) já apontaram para esse dilema enfrentado pelo pesquisador, que busca visibilidade e prestígio acadêmico advindo de artigo publicado em revista referendada. Segundo os atores, essa busca levaria o pesquisador a optar pelo artigo, visto que exige sigilo durante o processo, o que adiaria a sua publicação.

Sobre a questão da titularidade das patentes, Garnica, Oliveira e Torkomian (2006) trazem um ponto de debate importante sobre a divisão dos ganhos econômicos advindos de contratos de transferência de tecnologia para exploração de patentes. Para esses autores, o percentual de participação nos ganhos destinado aos inventores pode ser percebido como baixo, ainda mais se forem considerados exemplos de países como EUA e Israel, cujo percentual chega a $50 \%$. O artigo 13 da Lei n. 10.973/2004 (BRASIL, 2004) assegura ao inventor uma participação entre $5 \%$ a 33,3\% nos ganhos econômicos auferidos pela ICT resultantes de licenciamentos de tecnologia. Embora seja um progresso em relação à legislação anterior - a Lei n. 9.279/1996, que não estabelecia uma remuneração mínima para o inventor -, para os pesquisadores o percentual pode ser considerado baixo, a ponto de não motivá-los a requerer a proteção de suas invenções e preferir a publicação de artigos.

Nunes et al. (2013) concordam ao afirmar que os cientistas brasileiros preferem se dedicar à publicação de artigos e que a proteção das tecnologias desenvolvidas a partir de pesquisa aplicada ainda é pouco difundida. Para esses autores, apesar de existir um crescente interesse público para que o conhecimento produzido nas universidades e instituições de pesquisa seja transferido às indústrias, aspirando acelerar o processo de desenvolvimento econômico do país, falta uma política efetiva de integração e troca de conhecimentos entre universidade e empresa.

Sem a adequada proteção, o conhecimento tecnológico fica exposto para ser apropriado por aqueles que não investiram recursos para a sua produção. Nesse sentido, Martins, em 2010 já apontou as universidades como as maiores geradoras de ciência e tecnologia no Brasil, considerando o número de publicações científicas, mas observara que suas criações ainda não eram protegidas por patentes em todo seu potencial, deixando de gerar ganhos econômicos para a instituição, para o pesquisador e para o país.

\section{Metodologia}

Para o desenvolvimento deste trabalho, primeiramente foi realizada uma revisão da literatura, com o objetivo de conhecer e reunir publicações relacionadas às temáticas: tecnologia, inovação, patentes e empreendedorismo. De acordo com Marconi e Lakatos (2006), essa fase possibilita que se conheça o estado da arte em que se encontra a temática e permite que se obtenha uma referência inicial, que auxiliará na determinação das variáveis envolvidas. 
Quanto ao método utilizado, caracteriza-se como estudo de caso, um tipo de pesquisa cujo objeto é uma unidade que se analisa profundamente, neste caso, a Universidade Estadual de Maringá. O intervalo de tempo estabelecido para a análise foi o período de 2008 a 2018.

Para a coleta de dados, se fez necessária a realização de uma pesquisa documental para a análise de dados, bibliométrica, através de busca em bases de dados do portal de periódicos eletrônicos da Coordenação de Aperfeiçoamento de Pessoal de Nivel Superior (Capes). A base de dados para a pesquisa e análise da produção científica utilizada foi a Web Of Science, a qual permite a análise do conteúdo de mais de 20.000 revistas científicas mediante acesso a dados bibliográficos completos e curados. Por sua vez, a base de dados para a busca e análise de patentes foi a Derwent Inovattion Index, que coleta e organiza dados de 42 oficinas de patentes no mundo.

Para o acesso às bases de dados utilizadas, foi necessário o acesso remoto ao conteúdo assinado do Portal de Periódicos da Capes, um serviço provido pelas instituições de ensino à sua comunidade acadêmica através de login de usuário e senha, no campo de identificação denominado CAFE (Comunidade Acadêmica Federada) no portal.

Para a realização das buscas, na base Web of Science, utilizou-se a modalidade de pesquisa básica, assinalando-se o tópico "ano de publicação" e o campo "tempo estipulado" na opção "intervalo personalizado" e preenchendo-se o período estabelecido, 2008 a 2018, sem a inserção de palavras-chave. Após a geração do primeiro resultado de busca, procedeu-se com o refinamento dos registros apresentados selecionando-se na lista "Países/Regiões" a opção Brasil. Após a análise dos resultados para o país, realizou-se mais um refinamento selecionando-se na lista de "Organizações Aprimoradas" a opção Universidade Estadual de Maringá. Na análise dos registros apresentados para a UEM, utilizaram-se opções avançadas de refinamento ao selecionar a opção "analisar resultados", que apresenta opções mais detalhadas como tipos de documentos publicados, áreas, categorias, autores, agências financiadoras, relatórios de citações, entre outras.

Para buscas na Derwent, além do campo de tempo, preencheu-se o campo "depositante" selecionando-se a Universidade Estadual de Maringá.

Os resultados, após os refinamentos selecionados, foram importados para o Excel para a elaboração de gráficos, a fim de favorecer a visualização e interpretação dos dados.

\section{Resultados e Discussões}

\subsection{Indicadores de Produção Científica}

No que se refere à produção científica, a Universidade Estadual de Maringá se destaca entre as instituições de ensino superior brasileiras com maior número de publicações científicas. Uma busca na Web of Science, considerando-se o intervalo 2008-2018, evidenciou que as instituições de ensino e pesquisa brasileiras publicaram um total de 624.506 documentos científicos, dentre as quais a UEM ocupa o $21^{\circ}$ lugar pelo total de publicações. 
Tabela 1 - Produção científica das universidades brasileiras, 2008-2018

$\begin{array}{lcc} & \text { UniversidadE } & \text { DocumeNTOS NA WEB OF SCIENCE } \\ 1 & \text { Universidade de São Paulo } & 129.786 \\ 2 & \text { Universidade Estadual Paulista } & 44.758 \\ 3 & \text { Universidade Estadual de Campinas } & 42.204 \\ 4 & \text { Universidade Federal do Rio de Janeiro } & 36.874 \\ 5 & \text { Universidade Federal do Rio Grande do Sul } & 32.804 \\ 6 & \text { Universidade Federal de Minas Gerais } & 30.604 \\ 7 & \text { Universidade Federal de São Paulo } & 27.330 \\ 8 & \text { Universidade Federal do Paraná } & 19.579 \\ 9 & \text { Universidade Federal de Santa Catarina } & 18.954 \\ 10 & \text { Universidade Federal de Pernambuco } & 15.287 \\ 11 & \text { Universidade do Estado do Rio de Janeiro } & 15.167 \\ 12 & \text { Universidade de Brasília } & 15.130 \\ 13 & \text { Universidade Federal de São Carlos } & 13.590 \\ 14 & \text { Universidade Federal do Ceará } & 12.820 \\ 15 & \text { Universidade Federal Fluminense } & 12.812 \\ 16 & \text { Universidade Federal de Viçosa } & 12.758 \\ 17 & \text { Universidade Federal de Santa Maria } & 12.624 \\ 18 & \text { Universidade Federal da Bahia } & 9.895 \\ 19 & \text { Universidade Federal do Rio Grande do Norte } & 9.636 \\ 20 & \text { Universidade Federal de Goiás } & 9.513 \\ \mathbf{2 1} & \text { Universidade Estadual de Maringá } & \mathbf{8 . 5 2 1}\end{array}$

Fonte: Web of Science (2019)

Embora se apresente timidamente, quando comparada à USP, Unesp e Unicamp por exemplo, a ocupação da vigésima primeira posição pela UEM é apreciável. Fazendo-se um recorte das universidades do estado do Paraná, a UEM é a segunda com maior número de publicações científicas, ficando abaixo apenas da Universidade Federal do Paraná no período de 2008-2018 (Tabela 1). Uma busca na Web of Science refinando os resultados para o ano de 2018, especificamente, revela que a UEM mantém sua posição no estado. Ainda refinando os resultados, observou-se que a UEM ocupa a $26^{\mathrm{a}}$ posição quanto ao total de publicações científicas em 2018, quando publicou 1.094 documentos, o que representa 13,8\% do total de produções científicas produzidas neste ano. Mesmo perdendo algumas colocações em relação ao acumulado na década 2008-2018, a instituição ainda ocupa posição de destaque no país nesse quesito. 
Refinando a análise para áreas que mais produzem artigos na UEM, observou-se que as áreas de Agricultura, Engenharias e Química foram as que mais publicaram no intervalo de anos de publicação 2008-2018.

Figura 1 - Áreas com maior número de publicações científicas na UEM, 2008-2018

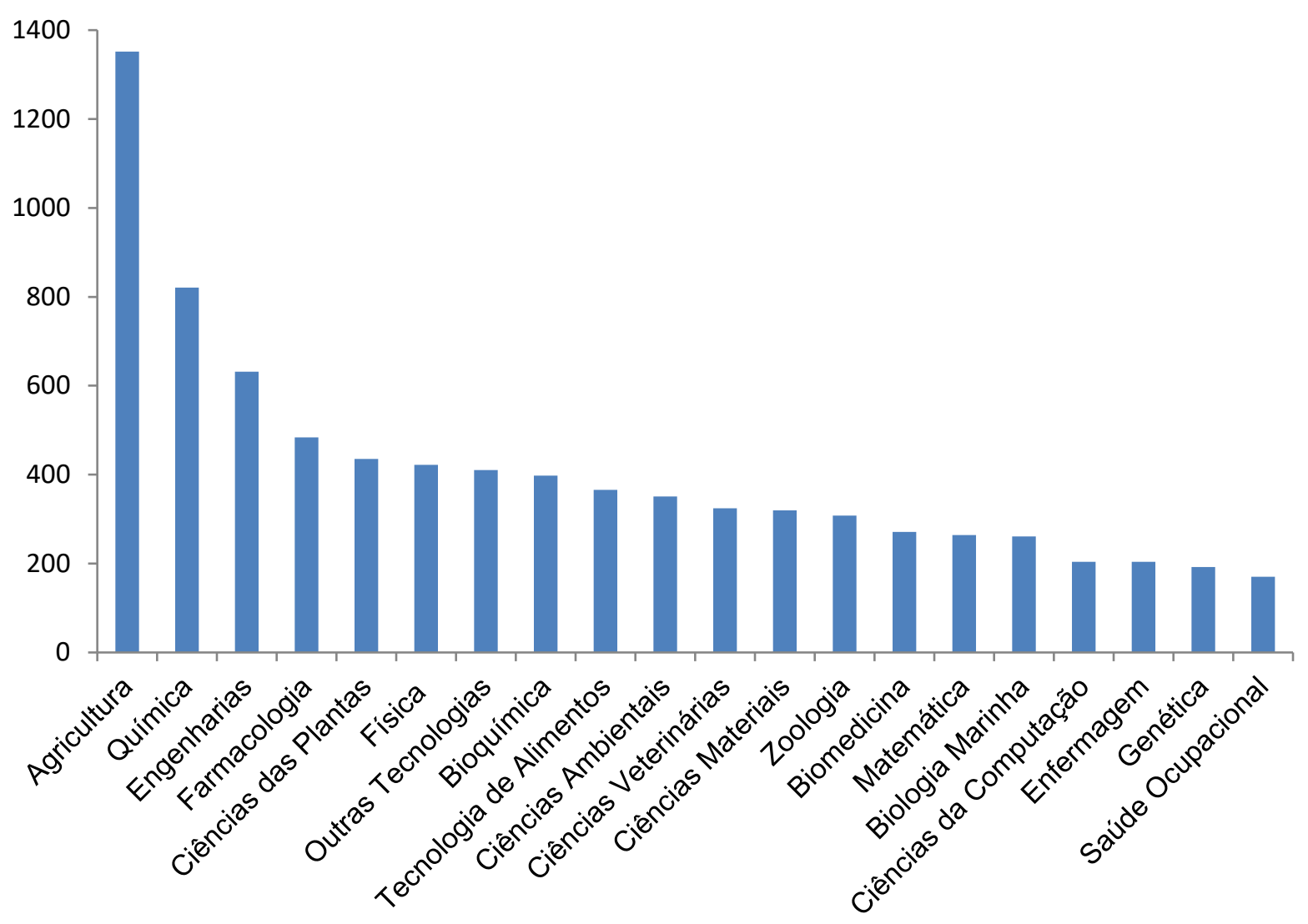

Fonte: Web of Science (2019)

Os resultados apontaram que no período de 2008-2018 a área de Agricultura foi responsável por mais de $15 \%$ das publicações científicas da UEM, com destaque também no número de publicações para a área de Química, com 820 documentos publicados - quase $10 \%$ do total, seguida da área de Engenharias, que, com 632 artigos, foi responsável por mais de 7\% das publicações.

\subsection{Indicadores de Produção Tecnológica}

A UEM registrou, no período 2008-2018 o total de 39 (trinta e nove) depósitos de pedido de patente, de acordo com a base de dados da Derwent Innovations Index. No gráfico abaixo estão apresentados os pedidos por área de classificação da Derwent. 
Figura 2 - Pedidos de Patente por área na Universidade Estadual de Maringá, 2008-2018

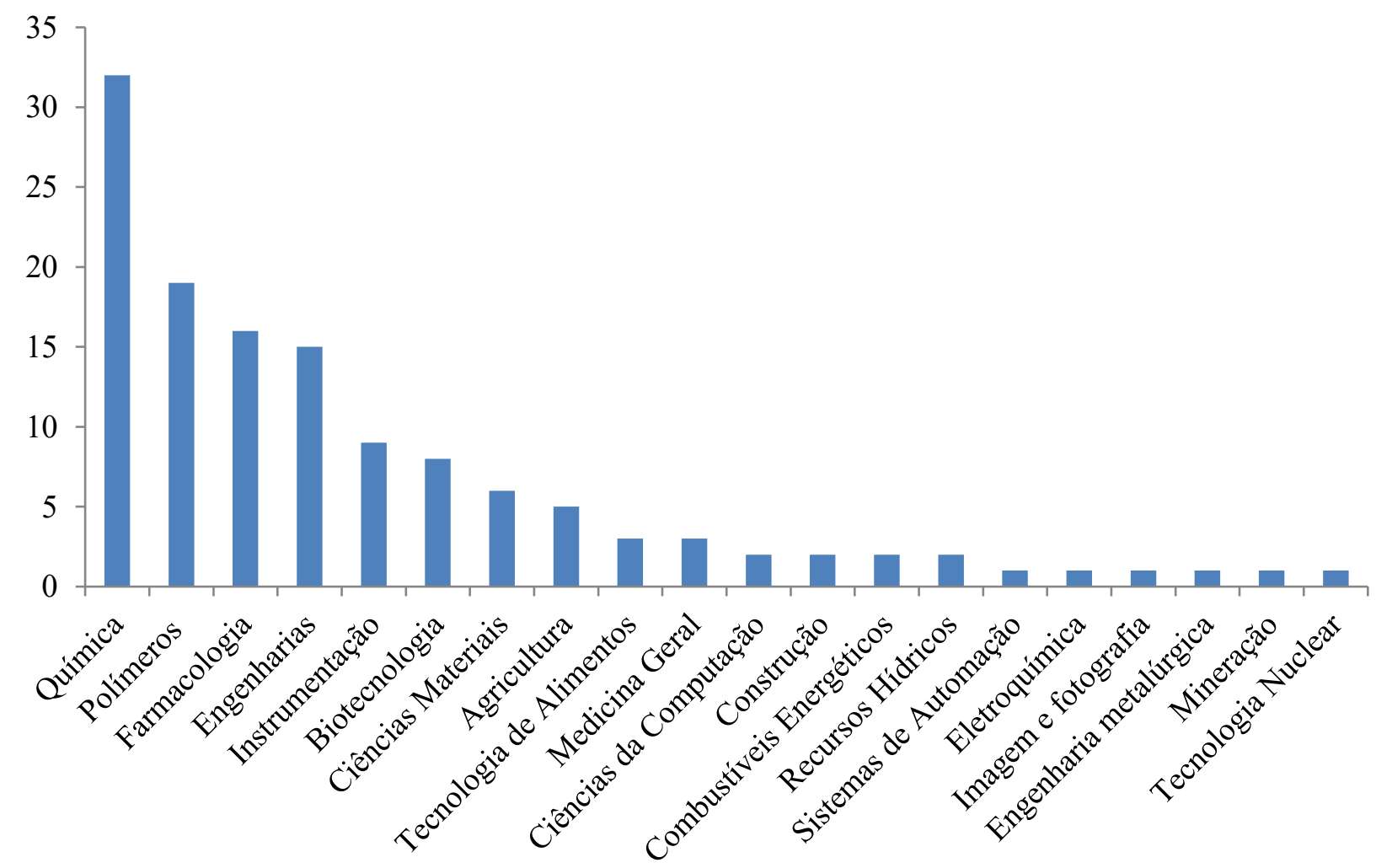

Fonte: Derwent Inovattion Index (2019)

Considerando-se o mesmo recorte de tempo que Cross, Thomson e Sinclair (2017), para fins de comparação, observou-se que para o período 2011-2016, dos 39 registros de pedidos de patentes da UEM, 32 (trinta e dois) são classificados pela Derwent como pertencentes a área de Química, o que representa mais de $80 \%$ do total de registros. Esse resultado converge com os indicadores de produção científica apresentados na Figura 1, na qual também se observa a Química entre as áreas com maior quantidade de publicações de artigos.

\subsection{Produção Científica versus Produção Tecnológica na UEM}

A fim de analisar comparativamente os indicadores de produção científica e os indicadores de produção tecnológica, considerou-se conveniente fazer um apanhado desses registros na última década para observá-los ano a ano. Os resultados estão representados na Figura 3. 
Figura 3 - Comparativo entre o número de artigos publicados e número de pedidos de patentes depositados pela UEM, 2008-2018

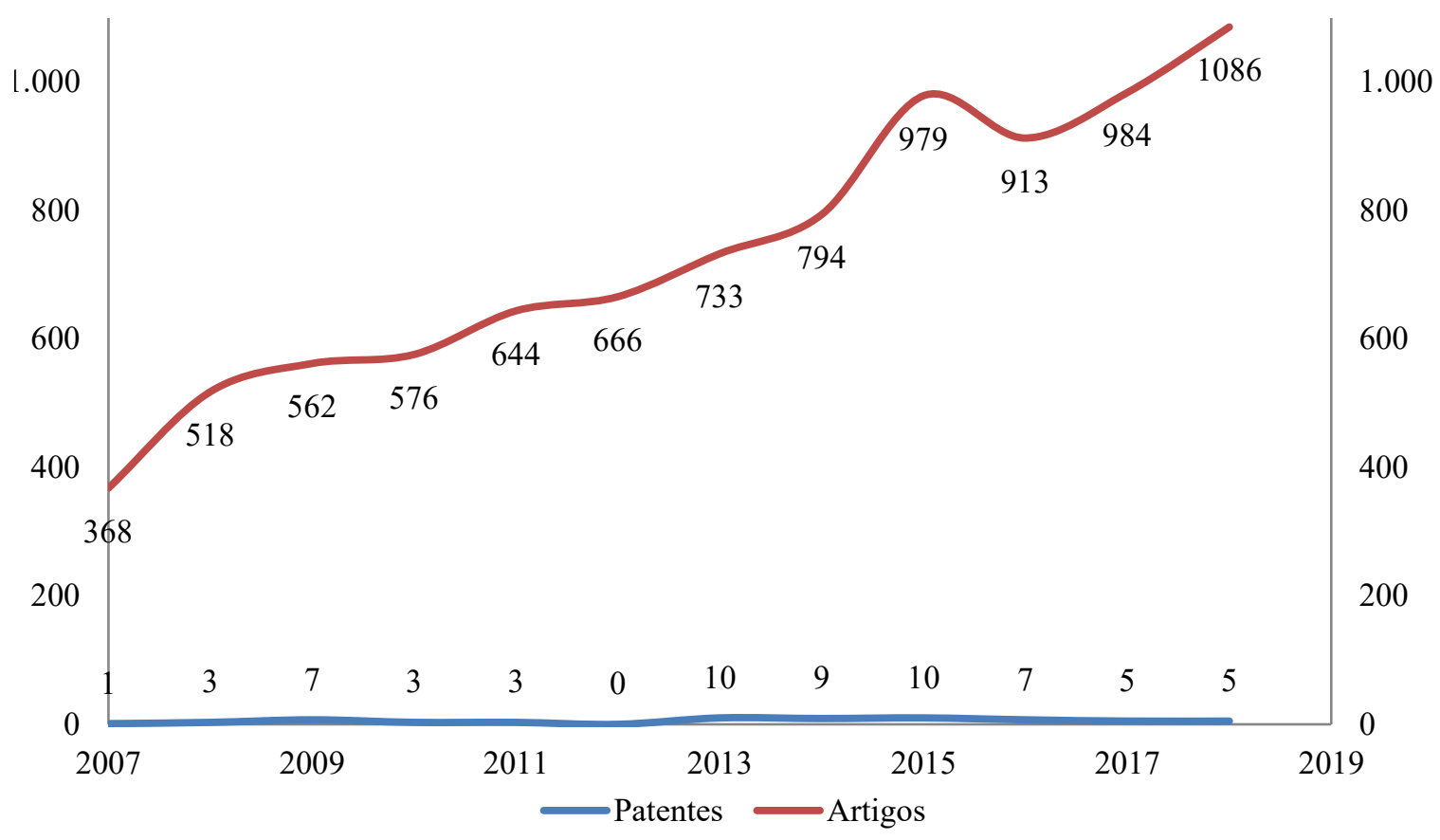

Fonte: Elaborado pelos autores deste artigo (2019)

A Figura 3 revela explicitamente que o número de artigos publicados se manteve em constante crescimento na UEM, enquanto o número de depósitos de pedidos de patentes não apresenta números expressivos e não tem um crescimento constante observado, o que sugere a ausência de ações ou políticas de incentivo ao desenvolvimento e patenteamento de tecnologias na universidade.

O resultado revela uma discrepância entre os números, pois os depósitos de patentes representam menos de $1 \%$ do total de artigos publicados anualmente. Na última década, de 2008 a 2018, foram publicadas mais de 8.500 produções científicas pela UEM, ao passo que no mesmo período foram depositados 62 (sessenta e dois) pedidos de registro de patentes.

Embora essa seja uma realidade observável em todas as instituições de ensino superior brasileiras, em que o número de pedidos de patentes está muito aquém do número de artigos publicados, pode-se dizer que na UEM esta distância está acentuada ao se delimitar como referência apenas as universidades que mais depositam patente no país. Como exemplo e para efeito de comparação, enquanto a UEM depositava cinco pedidos de patente em 2017, a Unicamp totalizava 77 registros.

Entretanto, é intrigante apurar que não se observa uma relação entre a produção científica e a produção tecnológica, ao passo que o número de publicações científicas não estabelece uma relação proporcional ao número de pedidos de patentes. Na Figura 4 pode-se verificar o total de pedidos de patentes depositados no ano de 2018 pelas 30 universidades que mais depositaram artigos científicos no Brasil. 
Figura 4 - Depósitos de pedidos de patentes nas universidades brasileiras que mais depositaram artigos científicos, 2018

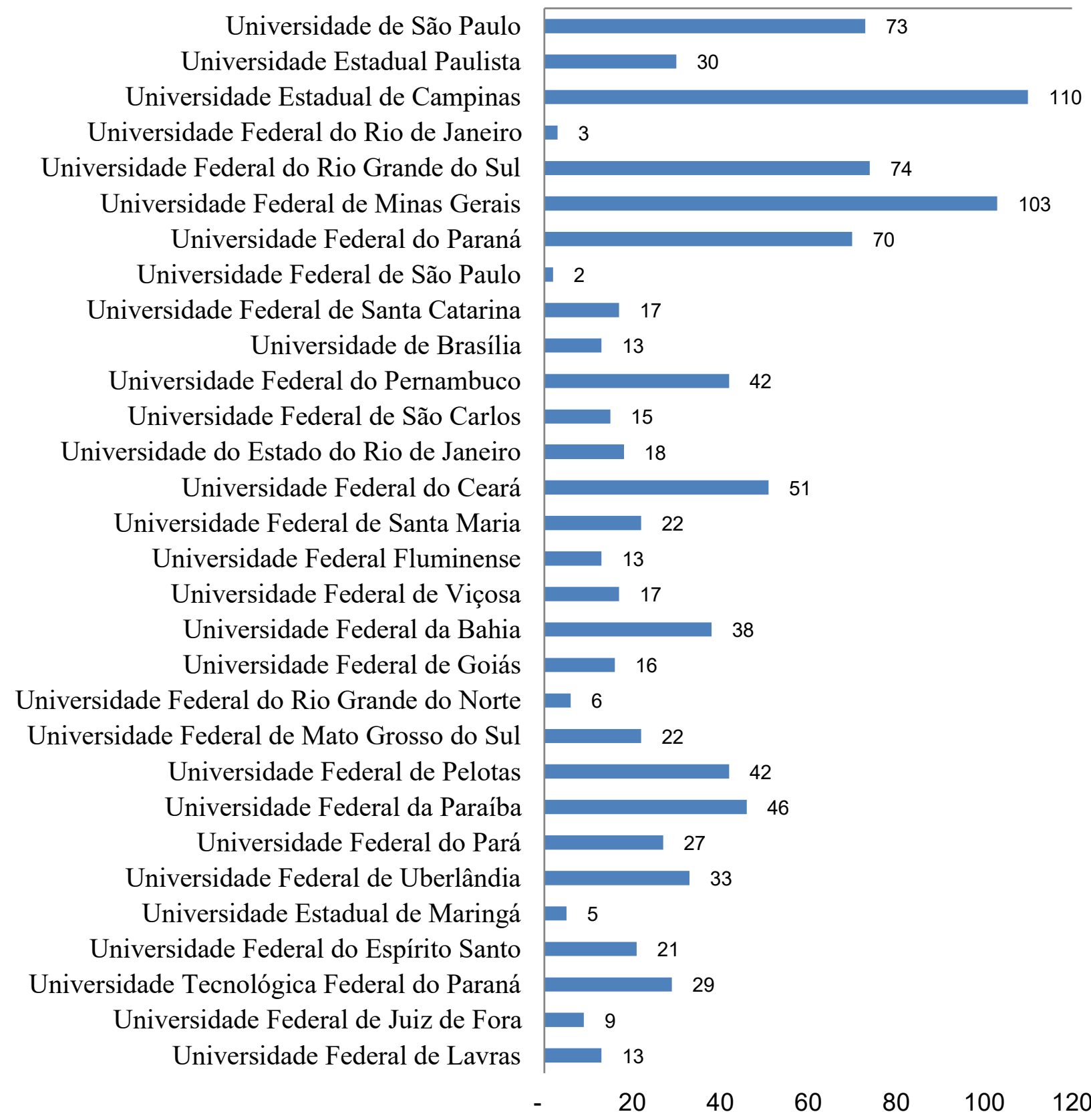

Fonte: Adaptado pelos autores deste artigo de Derwent Inovattion Index (2019)

Interessante observar que algumas universidades que mais publicaram artigos tiveram os mais baixos índices de depósitos de pedidos de patentes, como a Federal do Rio de Janeiro $e$ a Federal de São Paulo. Ao mesmo tempo, universidades com menor número de documentos publicados se destacaram em número de pedidos de patentes, como a Universidade Tecnológica Federal do Paraná e as Universidades Federal da Paraíba e Federal de Uberlândia. 


\section{Considerações Finais}

Conclui-se que na Universidade Estadual de Maringá a produção tecnológica está aquém da produção científica. Embora a instituição esteja entre aquelas que mais produzem artigos científicos nos país, seu desempenho, quando se trata de produção tecnológica e pedidos de registro de patentes, é exíguo. Surpreendentemente, seguindo a tendência dos resultados da maioria das universidades brasileiras, parece não haver uma relação entre a pesquisa básica e a pesquisa aplicada, visto que o número de pedidos de patentes depositados não foi proporcional ao número de artigos publicados.

É preocupante observar que, após mais de uma década dos estudos de Nunes e Oliveira (2007), o quadro da produção tecnológica para a inovação nas universidades não tenha sido alterado, que a importância da Propriedade Industrial ainda seja pouco percebida na UEM e no meio acadêmico brasileiro de forma geral, e que continue existindo um hiato entre produção tecnológica e produção científica, o inverso do que acontece em países desenvolvidos.

Mesmo com as importantes inclusões da inovação na legislação nos últimos anos, o resultado exíguo dos pedidos de patentes na universidade revela que é preciso pensar em novas formas e mecanismos para disseminar a pesquisa aplicada, a geração de tecnologias no contexto da inovação e a transferência de tecnologia, de forma a converter os conhecimentos produzidos na universidade em benefícios para toda a sociedade.

Os resultados da pesquisa apontaram as áreas tecnológicas com maior publicação na UEM: a área da Agricultura se destacou em publicações científicas e a da Química com o maior número de publicações de pedidos de patentes. O destaque da área de Química parece ser uma tendência nacional, uma vez que estudos de Jorge et al. (2018) a evidenciaram, especificamente a Química orgânica fina, como a área com maior número de reivindicações de pedidos de patentes no Brasil. No entanto, acredita-se que as áreas que se destacaram em maior número de publicações científicas e de patentes na UEM tenham relação com a economia da região de Maringá, voltada para agricultura e indústria.

Em tempo, é importante frisar que este trabalho não pretendeu minimizar o valor e a importância da produção científica de artigos e da pesquisa básica, mas pelo contrário, ratifica-se a importância de estudos que possam ser capazes de analisar as razões pelas quais o crescimento do número de depósitos de pedidos de patentes pelas universidades não ocorre na mesma proporção da produção de artigos. Apesar de constituir um importante indicador de inovação para o país, o número de pedidos de patentes depositados por si só não traz os benefícios que a inovação proporciona. Como exemplo do que aconteceu com as universidades chinesas, conforme apresentado num estudo de Gao et al. (2014), que embora tenham se engajado ativamente em atividades de solicitação de patente, um grande número desses produtos de inovação acadêmica não havia sido transferido para as indústrias. Como bem reforçam esses autores, invenções que não podem ser comercializadas são um grande desperdício de recursos e de recursos públicos.

Neste ponto, considera-se importante sublinhar que a inovação está na Constituição Federal Brasileira, o mais importante conjunto de regras do país. Incluída através da Emenda Constitucional n. 85, de 2015, explicita que promover a inovação deve ser prioridade do Estado, e neste estão compreendidas as universidades e instituições de ensino de forma geral. Assim, deve ser objetivo das universidades buscar a inovação e, de acordo com o texto da emenda, 
destinar a pesquisa tecnológica para a solução de problemas e desenvolvimento do sistema produtivo. Nessa visão, depreende-se que se o objetivo das instituições de ensino mudou, o papel do professor, por conseguinte, também, e que este também deve estar empenhado em promover a inovação através de sua prática docente.

Reconhece-se que a questão da produção de tecnologias comercializáveis e a produção de patentes na universidade é complexa, e que muito se relaciona com os dilemas que envolvem o papel do professor e da instituição de ensino - seja pela opção pela publicação de artigo científico para fins de currículo e prestígio acadêmico, seja por dúvidas quanto às questões de ganhos, o que cabe aos pesquisadores é a reflexão sobre os benefícios e malefícios para todos: pesquisador, a universidade e a sociedade.

Nesse sentido, embora discussões sobre a temática patentes e negócios, no contexto da universidade, venham crescendo nos últimos anos, ainda carecem de mais ações e incentivos por parte também das próprias instituições de ensino, a fim de incentivar e esclarecer dúvidas junto aos pesquisadores e seus laboratórios, buscando entender suas particularidades.

O estudo não se esgota e sugerem-se novos estudos que busquem identificar os fatores favoráveis e desfavoráveis ao depósito de pedidos de patentes nas universidades, bem como a transferência de tecnologia e desenvolvimento comercial de suas produções. Acredita-se que seja importante, também, realizar estudos que busquem analisar a ótica do pesquisador no contexto da pesquisa aplicada e do patenteamento das tecnologias. Discussões e debates sobre a temática do empreendedorismo e inovação no contexto da universidade são um relevante passo e podem trazer contribuições para a transformação da realidade deste contexto no país.

\section{Referências}

BRASIL. Lei n. 9.279, de 14 de maio de 1996. Regula direitos e obrigações relativos à propriedade industrial. Diário Oficial [da] República Federativa do Brasil, Brasília, DF, 1996. Disponível em: http://www.planalto.gov.br/ccivil_03/leis/L9279.htm. Acesso em: 4 out. 2018.

BRASIL. Lei n. 10.973, de 2 de dezembro de 2004. Dispõe sobre incentivos à inovação e à pesquisa científica e tecnológica no ambiente produtivo e dá outras providências. Diário Oficial [da]

República Federativa do Brasil, Brasília, DF, v. 3, 2004. Disponível em: http://www.planalto.gov. br/ccivil_03/_ato2004-2006/2004/lei/110.973.htm. Acesso em: 4 out. 2018.

CARVALHO, H. G.; REIS, D. R.; CAVALCANTE, M. B. Gestão da inovação. Curitiba-PR: Aymará Educação, 2011.

CATIVELLI, A. S.; LUCAS, E. O. Patentes universitárias brasileiras: perfil dos inventores e produção por área do conhecimento. Encontros Bibli: revista eletrônica de biblioteconomia e ciência da informação, [S.l.], v. 21, n. 47, p. 67-81, 2016. Disponível em: https://periodicos.ufsc.br/index. php/eb/article/viewFile/1518-2924.2016v21n47p67/32342. Acesso em: 28 jun. 2018.

CROSS, Di; THOMSON, Simon; SINCLAIR, Alexandra. Research in Brazil: a report for CAPES by Clarivative Analytics. Clarivative Analytics, 2017. Disponível em: http://www.capes.gov.br/images/ stories/download/diversos/17012018-CAPES-InCitesReport-Final.pdf. Acesso em: 5 jul. 2019.

DE BES, F.; KOTLER, P. A bíblia da inovação. São Paulo: Leya, 2011.

DERWENT INOVATTION INDEX [Base de dados - Internet]. Portal de Periódicos Capes. 
2019. Disponível em: http://www-periodicos-capes-gov-br.ez79.periodicos.capes.gov.br/?option=com plogin\&ym $=3 \& p d s \_$handle $=\&$ calling_system $=$ primo\&institute $=$ CAPES\&targetUrl $=\mathrm{http}: / / \mathrm{www}$-periodicoscapes-gov-br.ez79.periodicos.capes.gov.br\&Itemid=155\&pagina=CAFe. Acesso em: 5 jul. 2019.

GARNICA, Leonardo Augusto; OLIVEIRA, Rodrigo Maia de; TORKOMIAN, Ana Lúcia Vitale. Propriedade intelectual e titularidade de patentes universitárias: um estudo piloto na Universidade Federal de São Carlos-UFSCar. Anais [...] XXIV Simpósio de Gestão da Inovação Tecnológica, 2006. Disponível em: http://www.anpad.org.br/admin/pdf/DCT456.pdf. Acesso em: 14 jun. 2019.

GAO, X. et al. Technology transferring performance of Chinese universities: Insights from patent licensing data. Advances in Applied Sociology, v. 4, n. 12, p. 289, 2014. Disponível em: https:// file.scirp.org/Html/4-2290229_52511.htm\#p300. Acesso em: 9 nov. 2018.

GIMENEZ, A. M. N.; BONACELLI, M. B. M. Repensando o Papel da Universidade no Século XXI: Demandas e Desafios. Revista Tecnologia e Sociedade, [S.l.], v. 9, n. 18, 2013. Disponível em: http://www.redalyc.org/articulo.oa?id=496650340006. Acesso em: 5 jul. 2019. ISSN 1809-0044

JORGE, M. F.; et al. Indicadores de Propriedade Industrial 2018. Rio de Janeiro: Instituto Nacional da Propriedade Industrial - INPI, 2018. Disponível em: http://www.inpi.gov.br/sobre/ estatisticas/arquivos/pagina-inicial/indicadores-de-propriedade-industrial-2018_versao_portal.pdf. Acesso em: 05 jul. 2019.

MARCONI, M. A.; LAKATOS, E. M. Metodologia científica. São Paulo: Atlas, 2006.

MARTINS, W. H. Produção científica-Publicação versus patente: o caso CPGEI-UTFPR. 2010. Disponível em: http://www.pg.utfpr.edu.br/dirppg/ppgep/dissertacoes/arquivos/145/Dissertacao.pdf. Acesso em: 29 jun. 2018

MCTI - MINISTÉRIO DA CIÊNCIA, TECNOLOGIA E INOVAÇÕES E COMUNICAÇÕES.

Indicadores Nacionais de Ciência, Tecnologia e Inovação. 2017. Disponível em: https://www. mctic.gov.br/mctic/export/sites/institucional/indicadores/arquivos/Indicadores-2017.pdf. Acesso em: 27 set. 2018.

MUELLER, S. P. M.; PERUCCHI, V. Universidades e a produção de patentes: tópicos de interesse para o estudioso da informação tecnológica. Perspectivas em Ciência da Informação, v. 19, n. 2, p. 15-36, 2014. Disponível em: http://www.scielo.br/pdf/pci/v19n2/03.pdf Acesso em: 5 jul. 2019.

NARIAI, N. L.; AMARANTE, J. M. Obstáculos e Facilidades no Acesso ao Crédito pelas Empresas Incubadas na Incubadora Tecnológica de Maringá. Revista de Empreendedorismo, Inovação e Tecnologia, v. 4, n. 2, p. 82-101, 2017. Disponível em: https://seer.imed.edu.br/index.php/revistasi/ article/view/2406/1713. Acesso em: 2 mar. 2019.

NATIONAL SCIENCE BOARD (US). Science \& engineering indicators. National Science Board, 2018. Disponível em: https://www.nsf.gov/statistics/2018/nsb20181/digest/sections/preface\# Acesso em: 27 set. 2018

NEVES, D. P.; MANÇOS, G. Índice de universidades empreendedoras. São Paulo: Brasil Júnior, 2016. Disponível em: https://d335luupugsy2.cloudfront.net/cms\%2Ffiles\%2F19855\%2F1480 366506Livro+PDF+arrumado4.pdf. Acesso em: 2 mar. 2019.

NUNES, M. A. S. N.; et al. Discussões sobre produção acadêmico-científica \& produção tecnológica: mudando paradigmas. Revista GEINTEC-Gestão, Inovação e Tecnologias, [S.I.], v. 3, n. 2 , p. 205-220, 2013. Disponível em: http://www.revistageintec.net/index.php/revista/article/view/122. Acesso em: 3 ago. 2018. 
NUNES, J. S.; OLIVEIRA, L. G. Universidades Brasileiras - Utilização do Sistema de

Patentes de 2000 a 2004. Instituto Nacional da Propriedade Industrial, 2007. Disponível em: http://www.inpi.gov.br/menu-servicos/informacao/arquivos/universidades_brasileiras.pdf. Acesso em: 4 out. 2018.

TIDD, J.; BESSANT, J.; PAVITT, K. Gestão da inovação. 5. ed. Porto Alegre: Bookman, 2009.

WEB OF SCIENCE [Base de dados - Internet]. Portal de Periódicos Capes. 2019.

Disponível em: http://www-periodicos-capes-gov-br.ez79.periodicos.capes.gov.br/?option=com plogin\&ym $=3 \&$ pds_handle $=\&$ calling_system $=$ primo\&institute $=$ CAPES\&targetUrl $=\mathrm{http}: / / \mathrm{www}-$ periodicos-capes-gov-br.ez79.periodicos.capes.gov.br\&Itemid=155\&pagina $=\mathrm{CAFe}$. Acesso em: 5 jul. 2019.

\section{Sobre os Autores}

\section{Edione Magalhães Motta}

E-mail: edionemagalhaes1@gmail.com

Mestrado no Programa de Pós-graduação em Propriedade Intelectual e Transferência de Tecnologia para Inovação da Universidade Estadual de Maringá.

Endereço profissional: Avenida Frei Benjamim, n. 1.818, Bloco 2-203, Bairro Brasil, Vitória da Conquista, BA. CEP: 45051-555.

\section{José Roberto Dias Pereira}

E-mail: jrdp@dfi.uem.br

Doutorado no Programa de Pós-graduação em Física da Universidade Estadual de Campinas

Endereço profissional: Avenida Colombo, n. 5.790, Bloco G-67, Bairro Vila Esperança, Maringá, PR. CEP: 87020-900. 